\title{
KANDUNGAN MAGNETIT DAN DISTRIBUSI SEDIMEN PADA PANTAI ANOI ITAM, PULAU WEH
}

\section{MAGNETITE CONTENT AND SEDIMENT DISTRIBUTION ALONG ANOI ITAM BEACH, WEH ISLAND}

\author{
Syahrul Purnawan*, Irfan Kamal, Yopi Ilhamsyah, Sri Agustina, \\ Chitra Octavina, dan Adam Muhammad \\ Program Studi Ilmu Kelautan, Fakultas Kelautan dan Perikanan, Universitas Syiah Kuala \\ *E-mail: Syahrulpurnawan@unsyiah.ac.id
}

\begin{abstract}
The availability of iron sand in a region has an economic value, generally used as raw material for industry. On the other hand, mineral and magnetite deposits in sediments can be used as trace materials to predict sediment transport in an aquatic environment. This paper analyzes magnetite compositions along with average grain size parameters, used to interpret the magnetite distribution in the Anoi Itam Beach. Sediment samples were taken in February 2017 at 20 stations alongshore. The mean grain size parameter was obtained using the wet sieve method, while the magnetite content was separated using a strong magnet of Neodynium n-35. Anoi Itam sediments are characterized by a coarse texture, in which the slightly gravelly sand type is commonly found. The mean of sediment grain size ranged from 0.30 to $1.72 \mathrm{~mm}$, with $0.74 \mathrm{~mm}$ in average. The magnetite grain has a mean size from 0.31 to $1.82 \mathrm{~mm}$, and has an average of $0.76 \mathrm{~mm}$. High concentrations of magnetite content are found at the northern Anoi Itam thus lower toward the south, so it concluded that the magnetite distribution originated from the northern part of Anoi Itam Beach.
\end{abstract}

Keyword: Sabang, sediment, grain size, magnetite

\begin{abstract}
ABSTRAK
Keberadaan pasir besi dalam suatu wilayah memiliki peran ekonomis penting, umumnya dimanfaatkan sebagai bahan baku untuk industri. Di sisi lain, kandungan mineral dan magnetit dalam sedimen dapat digunakan sebagai bahan penjejak untuk menelusuri proses transport sedimen dalam suatu lingkungan perairan. Penelitian ini bertujuan memberikan gambaran pola distribusi magnetit di lingkungan Pantai Anoi Itam (PAI) yang berada di bagian timur Pulau weh, Kota Sabang. Analisis komposisi magnetit bersama dengan parameter ukuran butiran rata-rata, digunakan untuk mendeskripsikan pola sebaran pasir besi yang terbentuk pada kawasan PAI. Sampel sedimen diambil pada bulan Februari 2017 menggunakan coring pada 20 stasiun di sepanjang pantai (alongshore). Parameter ukuran butiran ratarata diperoleh menggunakan metode ayak basah, sedangkan kandungan magnetit dihasilkan dari separasi menggunakan magnet kuat Neodynium tipe n-35. Sedimen PAI dicirikan memiliki tekstur yang agak kasar, dimana tipe pasiran dengan sedikit kerikil (Slightly Gravelly Sand) umum ditemukan. Diperoleh nilai ukuran butiran rata-rata sedimen antara $0,30 \mathrm{~mm}$ hingga $1,72 \mathrm{~mm}$, dengan rerata (average) $0,74 \mathrm{~mm}$. Magnetit memiliki nilai ukuran butiran rata-rata antara $0,31 \mathrm{~mm}$ hingga $1,82 \mathrm{~mm}$, dan diperoleh rerata sebesar $0,76 \mathrm{~mm}$. Keterdapatan magnetit ditemukan dalam persentase yang tinggi pada bagian utara PAI dan menjadi lebih rendah menuju bagian selatan, sehingga disimpulkan bahwa pola sebaran magnetit berasal dari bagian utara PAI.
\end{abstract}

Kata kunci: Sabang, sedimen, ukuran butir, magnetit

\section{PENDAHULUAN}

Pulau Weh merupakan pulau kecil dengan topografi berbukit, dan dikelilingi perairan pantai yang banyak terdapat kawasan terumbu karang. Anoi Itam merupakan salah satu kawasan yang terkenal di Pulau Weh karena memiliki pantai dengan 
karakteristik unik, dimana sedimen yang terdapat pada pantai tersebut berwarna gelap. Sesuai dengan namanya, Anoi Itam dalam bahasa lokal berarti pasir hitam. Pantai Anoi Itam (PAI) terletak di sebelah timur Pulau Weh, berhubungan dengan Laut Andaman dan Selat Malaka. Berdekatan dengan Samudera Hindia, posisi Pulau Weh secara umum dipengaruhi oleh dua musim, yaitu muson timur laut dan muson barat daya (Diansky et al., 2006; Rizal et al., 2012; Schott et al., 2009; Shankar et al., 2002), dimana PAI mendapatkan paparan langsung dari pengaruh muson timur-laut.

Karakteristik sedimen Anoi Itam didominasi oleh pasir bertekstur medium hingga kasar, dengan warna abu-abu gelap. Warna gelap pada pasir daerah pantai dapat menandakan adanya kandungan mineral besi (Fe) (Saniah et al., 2015). Keberadaan mineral besi pada suatu wilayah dapat dimanfaatkan sebagai bahan baku industri yang memanfaatkan kandungan mineral besi (Zulkarnain et al., 2000). Mineral besi di alam biasa ditemukan dalam bentuk oksida besi seperti magnetit $\left(\mathrm{Fe}_{3} \mathrm{O}_{4}\right)$ yang lebih dominan ditemukan di alam dan juga lebih kuat sifat magnetisnya berbanding oksida besi lainnya seperti maghemite $\left(\gamma-\mathrm{Fe}_{2} \mathrm{O}_{3}\right)$ dan hematite $\left(\alpha-\mathrm{Fe}_{2} \mathrm{O}_{3}\right)$. Keterdapatan mineral besi pada Anoi Itam didukung oleh status Pulau Weh sebagai pulau vulcanik aktif (Dwipa et al., 2006; Sieh and Natawidjaja, 2000; Ueshima et al., 2013). Terdapat puncak gunung berapi aktif yang berada tepat di tengah Pulau Weh serta ditemukannya sejumlah aliran kecil (tributaries) air hangat yang mengalir hingga ke laut.

Endapan sedimen di suatu wilayah perairan berhubungan erat dengan sumber bebatuan induk dan juga gaya pengangkut (Beetham and Kench, 2014; Boretto et al., 2013; Schneider et al., 2016). Keberadaan sejumlah mineral, terutama mineral besi atau magnetit, pada suatu sedimen di perairan dapat dijadikan sebagai alat penjejak (trace) untuk mengamati pola distribusi sedimen pada suatu perairan ( Fan et al., 2018; Kissel et al., 2017; Lahijani and Tavakoli, 2012; Putra et al., 2013; Šmejda et al., 2017; Wu et al., 2017; Zahid and Barbeau, 2010). Penelusuran terhadap asal usul dan pola distribusi sedimen dapat juga menggunakan pendekatan parameter statistik butiran sedimen seperti ukuran butir rata-rata (mean grain size), pemilahan (sortation), kemencengan (skewness), dan kepuncakan (kurtosis) (Abdulkarim et al., 2011; Coltorti et al., 2015; Purnawan et al., 2015b, 2015a; Sierra et al., 2017; Wachecka-Kotkowska and Kotkowski, 2011).

Penelitian ini bertujuan untuk mendapatkan gambaran asal usul keberadaan pasir besi melalui pola distribusi dan kandungan magnetit di PAI. Kandungan magnetit yang ditemukan pada sedimen di PAI dapat dijadikan sebagai "fingerprint" dalam upaya membantu memahami pola distribusi magnetit atau pasir besi serta asalusulnya pada kawasan tersebut.

\section{METODE PENELITIAN}

\subsection{Pengumpulan Data Sedimen}

Pengambilan data sedimen dilakukan pada pada daerah lower littoral sebanyak 20 stasiun yang mewakili daerah PAI di sepanjang garis pantai (alongshore) bagian timur Pulau Weh (Gambar 1). Lokasi antara stasiun 10 dan 11 merupakan daerah tebing terjal, sehingga data sedimen tidak memungkinkan untuk diambil. Metode coring diaplikasikan untuk mengambil sampel sesuai dengan American Society for Testing and Materials D4823-95 (ASTM, 2014) menggunakan pipa paralon berdiameter 2.5 inchi dengan ketebalan lapisan sekitar $20 \mathrm{~cm}$. Waktu pengambilan sampel dilakukan pada bulan Februari 2017. 


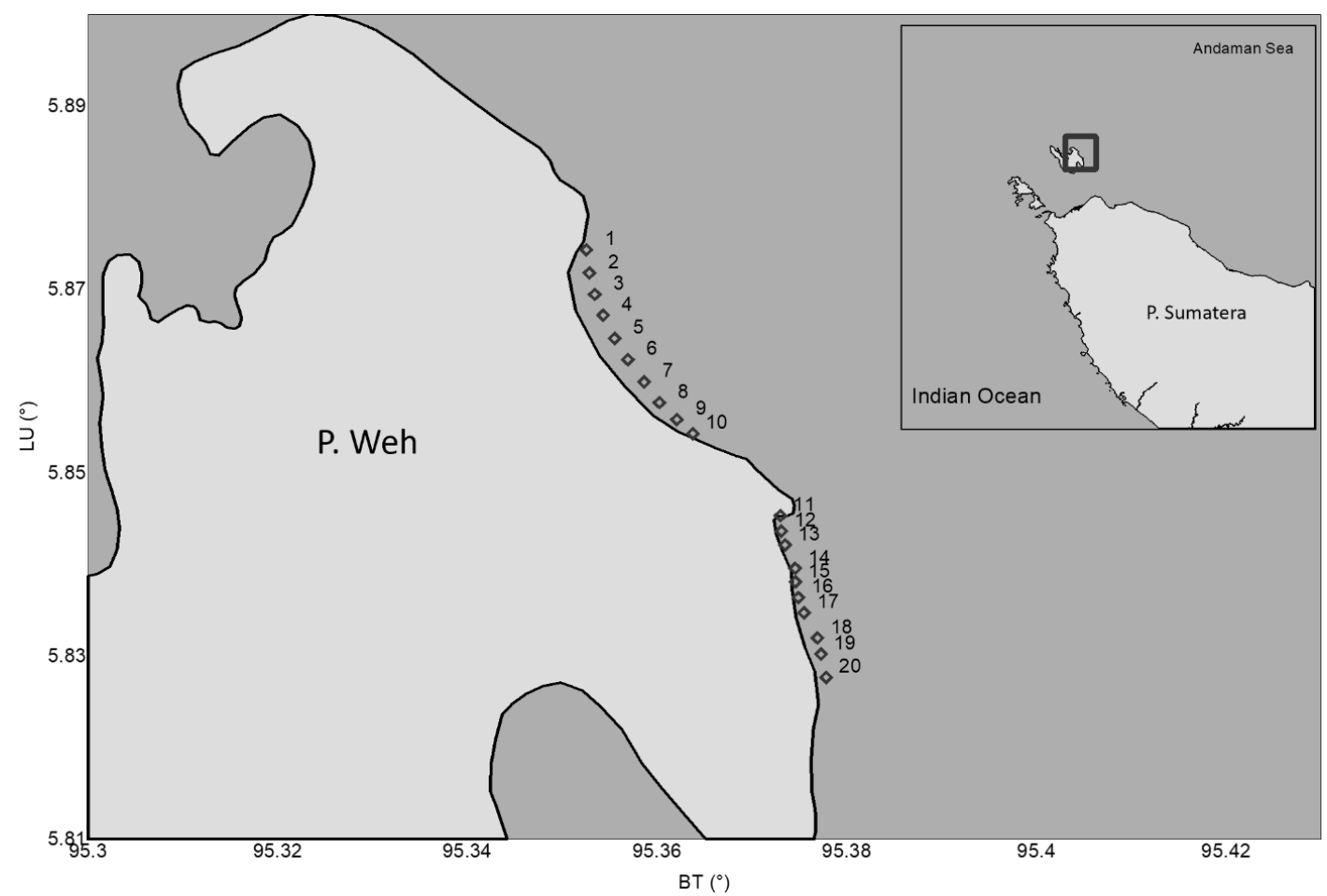

Gambar 1. Lokasi pengambilan sampel berada di sepanjang PAI, terdiri atas 20 stasiun.

\subsection{Analisis Sedimen}

Analisis sedimen dilakukan melalui proses separasi sedimen berdasarkan ukuran butiran. Separasi sedimen dilakukan menggunakan metode ayak basah dengan ukuran ayakan sesuai US standard sieve mesh: 10, 18, 35, 60, 120, 230 dan 400. Sedimen yang telah terpisah berdasarkan ukuran fraksi kemudian dikeringkan dan ditimbang berat per fraksinya.

Langkah selanjutnya adalah memisahkan kandungan magnetit dari setiap fraksi sedimen menggunakan Strong Magnet Neodynium tipe n-35. Magnetit yang terseparasi ditimbang kembali untuk diperoleh persentase bobot per fraksi menggunakan persamaan (1), sedangkan kandungan magnetit dari setiap stasiun merupakan hasil akumulasi dari nilai yang diperoleh dari setiap fraksi (2).

Persentase magnetite per fraksi $=$ $\underline{\text { bobot magnetite per fraksi }(g)}$

bobot total sediment $(g)$ persentase magnetite per stasiun $=$

Spersentase magnetite per fraksi

Setelah semua sampel berhasil diseparasi, dilanjutkan dengan perhitungan parameter statistik ukuran butir sedimen, baik untuk bulk sediment maupun magnetit. Perhitungan statistik sedimen mengikuti metode (Folk and Ward, 1957), berdasarkan skala metrik yang dikalkulasi menggunakan software Gradistat (Blott and Pye, 2001). Jenis sedimen ditentukan menggunakan segitiga Folk.

Penelitian ini membahas hasil analisis scoring yang menggabungkan persentase magnetit per fraksi dari setiap stasiunnya (3) dengan ukuran fraksi menggunakan persamaan:

\section{Scoring per stasiun $=$}

$\frac{\Sigma\left[\begin{array}{c}u k \text { kandun fraksi } k e-i(g) \\ {[\text { kan magnetite fraksi ke-i }(\%)}\end{array}\right]}{100}$

Hasil perhitungan ini menggabungkan stasiun yang memiliki kandungan magnetit dalam jumlah yang tinggi dan 
ukuran butiran magnetit yang kasar akan memiliki nilai scoring yang tinggi berbanding dengan stasiun yang memiliki kandungan magnetit yang rendah dan ukuran butir magnetit yang halus.

\section{HASIL DAN PEMBAHASAN}

\subsection{Hasil}

Terlihat bahwa fraksi lumpur pada hasil ayakan hanya memiliki nilai yang sangat kecil, kecuali pada stasiun 1, fraksi lumpur hanya bernilai $<1 \%$. Modus atau frekuensi kehadiran tertinggi dari sebaran sedimen banyak ditemukan berada pada fraksi pasir medium $(0,25 \mathrm{~mm})$. Terdapat sembilan stasiun yang memiliki modus pada fraksi pasir medium (medium sand), sementara terdapat tujuh stasiun yang memiliki modus pada pasir kasar (coarse sand). Sebanyak tiga stasiun terlihat memiliki modus yang berada pada fraksi kerikil (2 mm).

Tipe sedimen ditentukan berdasarkan segitiga Folk berdasarkan komposisi penyusun sedimen yang terdiri dari fraksi kerikil, pasir, dan lumpur (Tabel 1). Berbagai pola distribusi sedimen berdasarkan ukuran fraksi ini mengarahkan pada penentuan tipe sedimen yang berbeda-beda. Ditemukannya kandungan kerikil pada setiap stasiun menghasilkan tipe sedimen yang merujuk pada kehadiran kerikil pada sampel sedimen, seperti pasir sedikit berkerikil (slightly gravelly sand), pasir berkerikil (gravelly sand), dan kerikil berpasir (sandy gravel). Sedimen dengan tekstur pasir sedikit berkerikil adalah yang dominan ditemukan pada PAI.

Tabel 1. Sebaran ukuran butiran sedimen dan tipe sedimen pada PAI.

\begin{tabular}{rrrrrrrrl}
\hline \multirow{2}{*}{ St } & \multicolumn{1}{c}{ Persentase Berat (\%) } & \multicolumn{1}{c}{ Berdasarkan Ukuran Fraksi (mm) } & & \multirow{2}{*}{ Tipe } \\
\cline { 2 - 7 } & \multicolumn{1}{c}{1} & \multicolumn{1}{c}{0,5} & 0,25 & 0,125 & 0,063 & 0,038 & \\
\hline 1 & 30,30 & $65,70^{*}$ & 2,29 & 0,03 & 0,14 & 0,11 & 1,44 & Kerikil berpasir \\
3 & 2,65 & 11,70 & $81,85^{*}$ & 3,35 & 0,30 & 0,12 & 0,02 & Pasir sedikit berkerikil \\
4 & 0,33 & 17,51 & $48,85^{*}$ & 28,17 & 4,42 & 0,10 & 0,62 & Pasir sedikit berkerikil \\
5 & 1,30 & 12,75 & 39,71 & $42,70^{*}$ & 3,23 & 0,25 & 0,05 & Pasir sedikit berkerikil \\
6 & $0,68^{*}$ & 26,77 & 11,16 & 16,31 & 8,86 & 0,65 & 0,56 & Kerikil berpasir \\
7 & 1,75 & 5,71 & 43,28 & $43,47^{*}$ & 4,40 & 0,66 & 0,72 & Pasir sedikit berkerikil \\
8 & 1,32 & 3,74 & $65,33^{*}$ & 28,58 & 0,62 & 0,29 & 0,11 & Pasir sedikit berkerikil \\
9 & 2,35 & 7,39 & $53,89^{*}$ & 33,80 & 2,10 & 0,41 & 0,05 & Pasir sedikit berkerikil \\
10 & 1,68 & 7,04 & $82,64^{*}$ & 6,71 & 1,74 & 0,13 & 0,05 & Pasir sedikit berkerikil \\
11 & 1,51 & 1,37 & 19,95 & $59,90^{*}$ & 16,65 & 0,58 & 0,04 & Pasir sedikit berkerikil \\
12 & $40,46^{*}$ & 17,64 & 26,04 & 14,10 & 1,49 & 0,24 & 0,04 & Kerikil berpasir \\
13 & 0,24 & 0,82 & 17,66 & $68,93^{*}$ & 12,15 & 0,19 & 0,01 & Pasir sedikit berkerikil \\
14 & 12,79 & 8,71 & 34,16 & $38,33^{*}$ & 5,61 & 0,36 & 0,04 & Pasir berkerikil \\
15 & 2,11 & 0,93 & 6,23 & $64,44^{*}$ & 21,20 & 5,03 & 0,06 & Pasir sedikit berkerikil \\
16 & 17,17 & 30,88 & $43,36^{*}$ & 5,94 & 2,07 & 0,55 & 0,04 & Pasir berkerikil \\
17 & 21,10 & 10,45 & $34,41^{*}$ & 30,30 & 3,45 & 0,24 & 0,05 & Pasir berkerikil \\
18 & 0,26 & 2,00 & 32,97 & $51,64^{*}$ & 12,89 & 0,22 & 0,02 & Pasir sedikit berkerikil \\
19 & 9,67 & 8,24 & 29,74 & $45,96^{*}$ & 5,69 & 0,69 & 0,03 & Pasir berkerikil \\
20 & $48,53^{*}$ & 22,47 & 22,77 & 5,19 & 0,62 & 0,37 & 0,05 & Kerikil berpasir \\
\hline
\end{tabular}

Note: modus pada setiap stasiun ditandai dengan nilai yang memiliki tanda $\left({ }^{*}\right)$. 


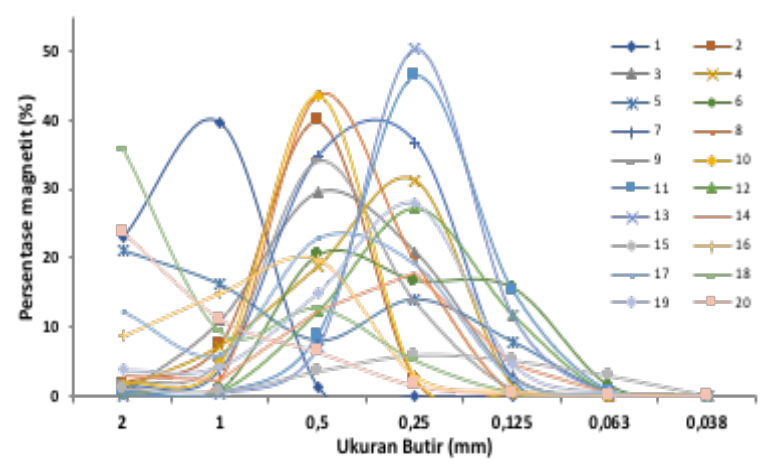

Gambar 2. Persentase magnetit (\%) per fraksi ukuran butir $(\mathrm{mm})$ pada setiap stasiun pengamatan di PAI. Keterdapatan magnetit pada setiap stasiun merupakan akumulasi nilai persentase magnetit dari setiap fraksi.

Persentase kandungan magnetit pada setiap fraksi ukuran sedimen diperoleh berdasarkan Persamaan 1, yang menunjukkan persentase magnetit per fraksi yang berbeda antar stasiun PAI (Gambar 2). Nilai akumulasi persentase magnetit pada tiap stasiun di PAI dihasilkan menggunakan persamaan 2, dimana ditemukan nilai persentase terkecil $(19,11 \%)$ pada stasiun 15 dan persentase tertinggi $(79,46 \%)$ pada stasiun 7. Berdasarkan persentase magnetit dari setiap stasiun PAI, maka diperoleh nilai rata-rata sebesar 57,11\%. Distribusi magnetit berdasarkan persentase magnetit pada PAI mengindikasikan keterdapatan magnetit dengan persentase yang lebih tinggi pada bagian utara dibandingkan bagian selatan PAI (Gambar 3).
Hasil separasi magnetit dari sampel sedimen (bulk of sediment) memiliki hal yang menarik untuk dikaji, khususnya terkait distribusi berdasarkan ukuran butiran magnetit (Tabel 2). Terdapat pola yang hampir serupa antara sebaran ukuran magnetit dengan ukuran butiran sedimen, secara spesifik tampak pada modus yang ditemukan berada pada fraksi yang sama, kecuali pada stasiun 8. Keadaan ini menunjukkan kecenderungan bahwa magnetit ditemukan tertinggi pada sekitar modus fraksi sedimen. Tipe atau tekstur magnetit juga cenderung memiliki kesamaan dengan sampel sedimen pada seluruh stasiun, kecuali pada stasiun 15 ditemukan tipe yang berbeda.

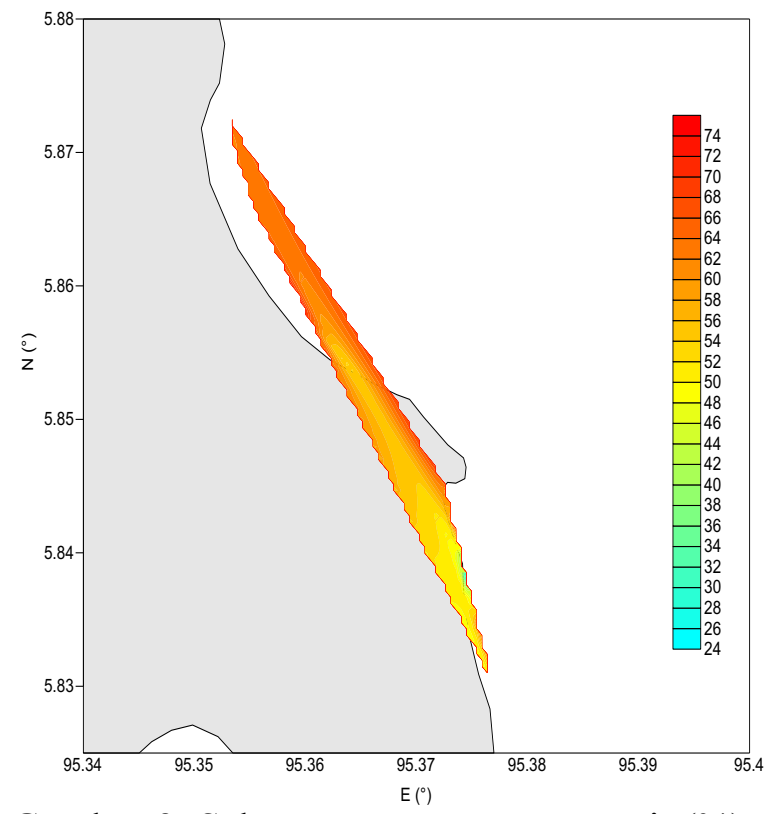

Gambar 3. Sebaran persentase magnetit (\%) dalam sedimen di PAI.

Tabel 2. Sebaran ukuran butiran magnetit dan tipe sedimen pada PAI.

\begin{tabular}{rrrrrrrrl}
\hline & \multicolumn{8}{c}{ Persentase Berat (\%) } \\
\cline { 2 - 7 } st & \multicolumn{1}{c}{2} & \multicolumn{1}{c}{1} & \multicolumn{1}{c}{0,5} & \multicolumn{1}{c}{0,25} & 0,125 & 0,063 & 0,038 & \multirow{2}{*}{ type } \\
\hline 1 & 35,94 & $61,63^{*}$ & 2,10 & 0,03 & 0,10 & 0,10 & 0,10 & Kerikil berpasir \\
2 & 3,29 & 14,54 & $77,55^{*}$ & 4,12 & 0,27 & 0,19 & 0,04 & Pasir sedikit berkerikil \\
3 & 0,37 & 16,97 & $45,51^{*}$ & 32,21 & 4,38 & 0,06 & 0,51 & Pasir sedikit berkerikil \\
4 & 1,57 & 12,13 & 31,44 & $52,30^{*}$ & 2,39 & 0,13 & 0,04 & Pasir sedikit berkerikil \\
5 & $31,34^{*}$ & 23,89 & 11,78 & 20,76 & 11,52 & 0,64 & 0,08 & Kerikil berpasir \\
6 & 1,68 & 1,48 & $36,50^{*}$ & 29,97 & 27,98 & 2,33 & 0,05 & Pasir sedikit berkerikil \\
7 & 1,60 & 4,85 & 43,77 & $46,23^{*}$ & 3,01 & 0,47 & 0,07 & Pasir sedikit berkerikil \\
\hline
\end{tabular}




\begin{tabular}{crrrrrrrl}
\hline \multirow{2}{*}{ st } & \multicolumn{1}{c}{ Persentase Berat (\%) Berdasarkan Ukuran Fraksi (mm) } & \multirow{2}{*}{ type } \\
\cline { 2 - 7 } & \multicolumn{1}{c}{1} & \multicolumn{1}{c}{0,5} & 0,25 & 0,125 & 0,063 & 0,038 & \\
\hline 8 & 1,23 & 3,66 & $65,33^{*}$ & 29,01 & 0,45 & 0,22 & 0,09 & Pasir sedikit berkerikil \\
9 & 3,27 & 9,32 & $60,94^{*}$ & 24,33 & 1,79 & 0,32 & 0,03 & Pasir sedikit berkerikil \\
10 & 3,14 & 8,89 & $82,93^{*}$ & 4,56 & 0,26 & 0,15 & 0,08 & Pasir sedikit berkerikil \\
11 & 0,84 & 0,61 & 12,30 & $64,39^{*}$ & 21,14 & 0,70 & 0,01 & Pasir sedikit berkerikil \\
12 & $56,46^{*}$ & 14,59 & 20,04 & 8,04 & 0,79 & 0,06 & 0,01 & Kerikil berpasir \\
13 & 0,05 & 0,40 & 10,11 & $72,61^{*}$ & 16,61 & 0,22 & 0,01 & Pasir sedikit berkerikil \\
14 & 7,35 & 5,44 & 30,39 & $44,84^{*}$ & 11,29 & 0,64 & 0,05 & Pasir berkerikil \\
15 & 5,41 & 3,49 & 18,58 & $30,93^{*}$ & 26,45 & 14,93 & 0,21 & Pasir berkerikil \\
16 & 18,33 & 31,82 & $42,31^{*}$ & 5,84 & 1,29 & 0,40 & 0,01 & Pasir berkerikil \\
17 & 19,39 & 9,52 & $36,57^{*}$ & 30,41 & 3,76 & 0,30 & 0,05 & Pasir berkerikil \\
18 & 0,25 & 1,08 & 23,45 & $52,39^{*}$ & 22,48 & 0,31 & 0,04 & Pasir sedikit berkerikil \\
19 & 6,61 & 7,68 & 26,78 & $49,80^{*}$ & 8,27 & 0,83 & 0,03 & Pasir berkerikil \\
20 & $55,12^{*}$ & 25,77 & 14,77 & 3,44 & 0,62 & 0,20 & 0,08 & Kerikil berpasir \\
\hline
\end{tabular}

Note: modus pada setiap stasiun ditandai dengan nilai yang memiliki tanda $\left(^{*}\right)$.

Perhitungan terhadap parameter statistik sedimen dilakukan menggunakan nilai ukuran butir rata-rata (mean grain size). Seperti halnya sebaran ukuran yang telah ditulis di atas, nilai ukuran butir rata-rata antara sedimen dan magnetit juga tidak memperlihatkan selisih nilai yang cukup jauh. Diperoleh nilai ukuran butir rata-rata sedimen antara $0,30 \mathrm{~mm}$ hingga $1,72 \mathrm{~mm}$, dengan rerata (average) yang diperoleh adalah 0,74 $\mathrm{mm}$, sedangkan nilai ukuran butir rata-rata dari magnetit berkisar antara $0,31 \mathrm{~mm}$ hingga $1,82 \mathrm{~mm}$ dengan nilai rerata sebesar $0,76 \mathrm{~mm}$. Adapun hasil perhitungan nilai ukuran butir rata-rata pada Anoi Itam disajikan pada Gambar 4.

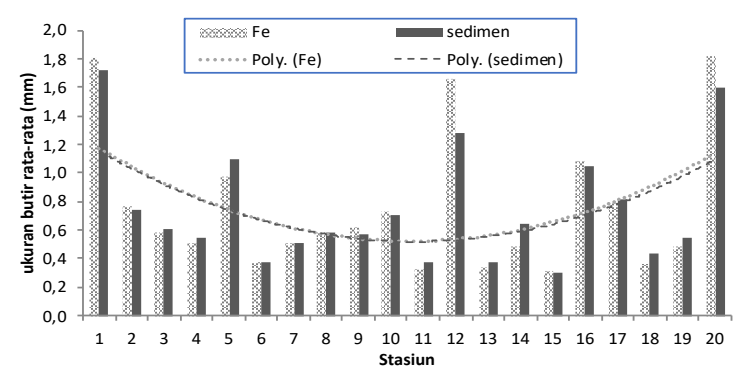

Gambar 4. Nilai mean grain size untuk sedimen dan magnetit $(\mathrm{Fe})$ pada PAI. Garis putus-putus menunjukkan kecenderungan pola hubungan (trendline) yang terbentuk dari nilai ukuran butiran rata-rata pada seluruh stasiun di PAI.

\subsection{Pembahasan}

Sedimen yang ditemukan di PAI dominan berfraksi pasir dan campuran kerikil, dengan kehadiran fraksi lumpur dalam jumlah yang sangat sedikit. Kondisi ini menghasilkan tektur yang kasar pada sedimen PAI, yang terdeskripsikan juga pada tipe sedimen yang diperoleh (Tabel 1). Kehadiran magnetit pada PAI sudah dapat ditilik sebelumnya melalui pengamatan secara visual yang berwarna gelap dan mengkilap, menandakan kemungkinan terdapatnya kandungan besi (Fe) dan titanium (Ti). Umumnya kandungan besi yang terdapat dalam sedimen di pantai tidak dalam bentuk unsur, namun dalam bentuk senyawa, yaitu $\mathrm{Fe}_{3} \mathrm{O}_{4}$ berupa mineral dengan sifat magnetis yang paling sering ditemui di alam. Begitu juga dengan kehadiran titanium (Ti) yang umumnya ditemukan dalam senyawa ilmenite $\left(\mathrm{FeTiO}_{3}\right)$ atau titanium oksida $\left(\mathrm{TiO}_{2}\right)$. Kehadiran mineral besi dan titanium pada suatu daerah sering kali dikaitkan dengan proses magmatik yang telah terjadi pada masa lampau, dimana kandungan $\mathrm{Fe}$ 
dan $\mathrm{Ti}$ yang terdapat pada sedimen merupakan hasil dari crystallization saat magma keluar dari perut bumi. Hal ini sejalan dengan adanya kajian yang menyebutkan bahwa Pulau Weh merupakan pulau vulkanik (Dwipa et al., 2006; Ueshima et al., 2013), dimana hingga saat ini bukti adanya proses vulkanik juga masih dapat dengan mudah ditemui di Pulau Weh seperti adanya sumber air panas.

Penelusuran terhadap sumber bebatuan besi merupakan tujuan dari penelitian ini, dimana berdasarkan pengamatan yang telah dilakukan pada saat pengambilan data ditemui sejumlah aliran kecil yang berasal dari daratan menuju lautan. Aliran kecil seperti ini terkadang dapat dikaitkan dengan proses transpor sedimen yang berasal dari daerah yang lebih tinggi menuju kawasan pengendapan di pantai (Purnawan et al., 2015b). Sedimen yang dekat dengan induk bebatuan umumnya memiliki ciri ukuran yang lebih besar dan kandungan mineral yang lebih tinggi, dan nilai-nilai tersebut akan semakin kecil seiring makin menjauh dari induk bebatuan (Garzanti et al., 2017; Narayana et al., 2017).

Pola sebaran kandungan magnetit yang terdapat pada PAI (Gambar 2), memperlihatkan adanya persentase yang lebih tinggi pada bagian utara PAI, dan secara gradual menunjukkan pola yang semakin sedikit menuju bagian selatan PAI. Penjelasan ini coba diperkuat dengan nilai mean grain size yang diperoleh (Gambar 3), yang memperlihatkan tektur yang lebih kasar pada ujung utara dan ujung selatan PAI, dimana tren tersebut juga menunjukkan adanya penurunan nilai ukuran butir rata-rata (mean grain size) pada kawasan tengah PAI.

Parameter ukuran butir rata-rata pada kawasan PAI tidak cukup baik dijadikan sebagai indikator tunggal pola distribusi dan kedekatan dengan induk bebatuan pasir besi. Hal ini terjadi akibat saat sedimen memasuki kawasan perairan, maka terdapat sejumlah proses lainnya yang turut mengontrol fungsi nilai ukuran butir rata-rata (Abdulkarim et al., 2011; Armaroli et al., 2013; Buscombe and Masselink, 2006; Purnawan et al., 2016; Reis and Gama, 2010; Samsuddin, 1989). Dalam kasus ini terdapat kemungkinan bahwa perbedaan ukuran butir rata-rata yang diperoleh juga merupakan fungsi level energi yang bekerja pada kawasan tersebut, dimana energi yang terdapat pada kawasan PAI memilah butiran kasar dan halus berdasarkan tingkatan energi yang terjadi pada kawasan tersebut. Pada kawasan yang memiliki nilai ukuran butir rata-rata yang tinggi dapat diartikan sebagai daerah yang memiliki level energi yang tinggi pula, sehingga butiran yang lebih halus akan terangkat dan dipindahkan menuju daerah pengendapan yang baru dengan level energi yang lebih rendah (Baldock et al., 2011; Beetham and Kench, 2014; Lau et al., 2015; Masselink et al., 2014; Mendoza et al., 2014). Perbedaan level energi yang bekerja pada daerah pantai sangat erat kaitannya dengan gelombang dan keterbukaan dan keterlindungan terhadap pengaruh gaya dari luar (Daly et al., 2014; Kuriyama and Banno, 2016; Mendoza et al., 2014). Di sisi lain, Pantai Anoi Itam tercatat memiliki kelerengan pantai yang berbeda (Purnawan et al., 2018), yang dapat mendorong perbedaan energi dan ukuran butiran yang dihasilkan pada kawasan tersebut (Jiang et al., 2015; Reis and Gama, 2010; Van Rijn et al., 2011).

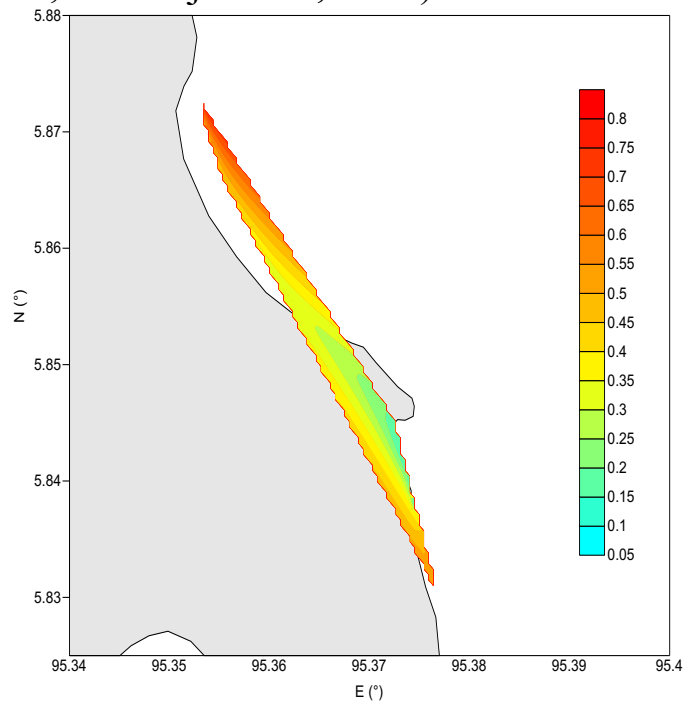

Gambar 5. Hasil scoring kandungan magnetit pada PAI, Pulau Weh. 
Pendekatan yang dilakukan paper ini untuk mendapatkan pola distribusi magnetit pada PAI adalah berdasarkan Persamaan 3. Hasil yang diperoleh dari Persamaan 3 menggabungkan parameter ukuran butir ratarata dari magnetit serta persentase magnetit dalam sedimen di PAI Pulau Weh. Interpolasi dilakukan untuk mendapatkan gambaran pola sebaran magnetit secara menyeluruh di PAI (Gambar 5). Keberadaan magnetit lebih terkonsentrasi pada daerah utara PAI dan jumlahnya menurun menuju selatan, meskipun pada ujung selatan (dekat stasiun 20) terdapat peningkatan persentase magnetit.

Berdasarkan sejumah pemaparan yang telah dibahas sebelumnya, maka diduga kuat bahwa pola sebaran magnetit pada kawasan PAI berasal dari utara dan terdistribusi hingga ke selatan di sepanjang garis pantai (alongshore) Anoi Itam. Kondisi ini mungkin saja turut dipengaruhi oleh pola arus yang terbentuk di sisi timur Pulau Weh yang berhadapan dengan Laut Andaman, dimana Rizal et al. (2012) memaparkan pola arus yang bergerak menuju Pulau Weh sebagian berasal dari arah timur-laut (northeast) Laut Andaman.

\section{KESIMPULAN}

Sedimen pada PAI didominasi oleh kandungan pasir, dengan campuran fraksi kerikil. Ukuran butiran rata-rata magnetit memiliki nilai yang cenderung serupa dengan yang dihasilkan oleh sampel sedimen. Nilai Ukuran butiran ini ditemukan kasar pada masing-masing ujung utara dan selatan, dan lebih halus pada bagian tengah PAI. Keterdapatan magnetit yang ditemukan dengan persentase yang lebih tinggi pada daerah utara menjelaskan bahwa distribusi magnetit pada PAI berasal dari daerah tersebut, yang dipertegas dengan hasil scoring yang mengungkapkan hal yang serupa.

\section{UCAPAN TERIMA KASIH}

Penulis mengucapkan terima kasih kepada anonymous reviewer yang telah banyak memberikan masukan dan arahan dalam menghasilkan tulisan yang lebih baik pada paper ini. Penulis juga berterima kasih kepada Muntazir, S.Pi. dan Muchlis, S.Kel. yang telah membantu dalam proses analisis data sedimen di laboratorium.

\section{DAFTAR PUSTAKA}

Abdulkarim, R., A.E. Akintoye, I.D. Oguwuike, T. Imhansoeleva, M. Philips, F.B. Ruth, S.O. Olubukola, J.O. Rasheed, A. Oluwaseun, M. Philips, F.B. Ruth, S.O. Olubukola, J.O. Rasheed, and A. Oluwaseun. 2011. Sedimentological variation in beach sediments of the barrier bar lagoon coastal system, South Western Nigeria. Nat. Sci., 9:19-26.

Armaroli, C., E. Grottoli, M.D. Harley, and P. Ciavola. 2013. Beach morphodynamics and types of foredune erosion generated by storms along the Emilia-Romagna coastline, Italy. Geomorphology, 199:22-35. doi: $\quad 10.1016 /$ j.geomorph.2013.04. 034.

American Society for Testing and Materials [ASTM]. 2014. Standard guide for core sampling submerged, unconsolidated sediments. ASTM International. West Conshohocken. $95 \mathrm{p}$.

Baldock, T.E., J.A. Alsina, I. Caceres, D. Vicinanza, P. Contestabile, H. Power, and A. Sanchez-Arcilla. 2011. Largescale experiments on beach profile evolution and surf and swash zone sediment transport induced by long waves, wave groups and random waves. Coast. Eng., 58: 214-227. doi: 10.1016/j.coastaleng.2010.10.006.

Beetham, E.P. and P.S. Kench. 2014. Wave energy gradients and shoreline change on Vabbinfaru platform, Maldives. 
Geomorphology, 209: 98-110. doi: 10.1016/j.geomorph.2013.11.029.

Blott, S.J. and K. Pye. 2001. GRADISTAT: a grain size distribution and statistics package for the analysis of unconsolidated sediments, Earth Surface Processes and Landforms, 26(11):1237-1248. doi: 10.1002/ esp.261.

Boretto, G.M., S. Gordillo, M. Cioccale, F. Colombo, and E. Fucks. 2013. Multiproxy evidence of late quaternary environmental changes in the coastal area of Puerto Lobos (northern Patagonia, Argentina). Quat. Int., 305: 188-205. doi: 10.1016/j.quaint. 2013.02.017.

Buscombe, D. and G. Masselink. 2006. Concepts in gravel beach dynamics. Earth-Science Rev., 79:33-52. doi: 10.1016/J.EARSCIREV.2006.06.003.

Coltorti, M., P. Pieruccini, P. Montagna, and F. Zorzi. 2015. Stratigraphy, facies analysis and chronology of Quaternary deposits at Capo S. Marco (Sinis Peninsula, west Sardinia, Italy). Quat. Int., 357: 158-175. doi: 10.1016/j.quaint.2014.03.033.

Daly, C. J., K.R. Bryan, and C. Winter. 2014.

'Wave energy distribution and morphological development in and around the shadow zone of an embayed beach', Coastal Engineering. Elsevier B.V., 93, pp. 40-54. doi: 10.1016/j.coastaleng. 2014.08.003.

Diansky, N.A., V.B. Zalesny, S.N. Moshonkin, and A.S. Rusakov. 2006. High resolution modeling of the monsoon circulation in the Indian Ocean. Oceanology, 46: 608-628. doi: 10.1134/S000143700605002X.

Dwipa, S., S. Widodo, E. Suhanto, and D. Kusnadi. 2006. Integrated geological, geochemical and geophysical survey in Jaboi geothermal field, Nangro Aceh Darussalam, Indonesia. in: Proceedings of the $7^{\text {th }}$ Asian
Geothermal Symposium. 121-126 pp.

Fan, J., J. Xiao, R. Wen, S. Zhang, Y. Huang, J. Yue, X. Wang, L. Cui, H. Li, D. Xue, and Y. Liu. 2018. Mineralogy and carbonate geochemistry of the Dali Lake sediments: Implications for paleohydrological changes in the East Asian summer monsoon margin during the Holocene. Quat. Int., 1-10. doi: 10.1016/j.quaint.2018.03.019.

Folk, R.L., and W.C. Ward. 1957. Brazos River bar: a study in the significance of grain size parameters. J. Sediment. Petrol,. 27:3-26. doi: 10.1098/rspa. 1963.0204.

Garzanti, E., P. Dinis, P. Vermeesch, S. Andò, A. Hahn, J. Huvi, M. Limonta, M. Padoan, A. Resentini, M. Rittner, and G. Vezzoli. 2017. Dynamic uplift, recycling, and climate control on the petrology of passive-margin sand (Angola). Sediment. Geol., 1-19. doi: 10.1016/j.sedgeo.2017.12.009.

Jiang, C., Z. Wu, J. Chen, B. Deng, and Y. Long. 2015. Sorting and sedimentology character of sandy beach under wave action. Procedia Engineering, 116(1):771-777. doi: 10.1016/j.proeng.2015.08.363.

Kissel, C., Z. Liu, J. Li, and C. Wandres. 2017. Magnetic signature of river sediments drained into the southern and eastern part of the South China Sea (Malay Peninsula, Sumatra, Borneo, Luzon and Taiwan). Sediment. Geol., 347: 10-20. doi: 10.1016/j.sedgeo.2016.11.007.

Kuriyama, Y. and M. Banno. 2016. Shoreline change caused by the increase in wave transmission over a submerged breakwater due to sea level rise and land subsidence. Coastal Engineering, 112:9-16. doi: 10.1016/ j.coastaleng.2016.02.003.

Lahijani, H. and V. Tavakoli. 2012. Identifying provenance of South Caspian coastal sediments using mineral distribution pattern. Quat. 
Int., 261:128-137. doi: 10.1016/j. quaint.2011.04.021.

Lau, A.Y.A., J.P. Terry, A.D. Switzer, and J. Pile. 2015. Advantages of beachrock slabs for interpreting high-energy wave transport: Evidence from ludao island in south-eastern Taiwan. Geomorphology, 228: 263-274. doi: 10.1016/j.geomorph.2014.09.010.

Masselink, G., M. Austin, T. Scott, T. Poate, and P. Russell. 2014. Role of wave forcing, storms and NAO in outer bar dynamics on a high-energy, macrotidal beach. Geomorphology, 226: 76-93. doi: 10.1016/j.geomorph. 2014.07.025.

Mendoza, E., R. Silva, B. Zanuttigh, E. Angelelli, T Lykke-Andersen, L. Martinelli, J.Q.H. Nørgaard, and P. Ruol. 2014. Beach response to wave energy converter farms acting as coastal defence. Coast. Eng., 87: 97111. doi: 10.1016/j.coastaleng. 2013.10.018.

Narayana, A.C., V. Prakash, P.K. Gautam, and S. Tripathi. 2017. Holocene environmental changes as recorded in sediments of a paleodelta, southwest coast of India. Quat. Int., 443: 115123. doi: 10.1016/j.quaint. 2017.04.016.

Purnawan, S., T.P.F. Alamsyah, I. Setiawan, T. Rizwan, M. Ulfah, dan S.A. El Rahimi. 2016. Analisis sebaran sedimen di Teluk Balohan Kota Sabang. J. Ilmu dan Teknologi Kelautan Tropis, 8: 531-538.

Purnawan, S., H.A. Haridhi, I. Setiawan, dan M. Marwantim. 2015a. Parameter statistik ukuran butiran pada sedimen berpasir di muara Kuala Gigieng, Kabupaten Aceh Besar. J. Ilmu dan Teknologi Kelautan Tropis, 7:15-22.

Purnawan, S., I. Setiawan, and Z.A. Muchlisin. 2015b. Sediment grainsize distribution in the Lake Laut Tawar, Aceh Province, Indonesia. AACL Bioflux, 8:161-164.
Purnawan, S., N.A. Mailala, S. Karina, Muhammad, I. Setiawan, and Y. Ilhamsyah. 2018. The beach slopes and grain size distribution at Anoi Itam and Pasir Putih Beaches, Sabang City. in IOP Conference Series: Earth and Environmental Science 176. p. 012013. IOP Publishing.

Putra, P.S., Y. Nishimura, Y. Nakamura, and E. Yulianto. 2013. Sources and transportation modes of the 2011 Tohoku-Oki tsunami deposits on the central east Japan coast. Sediment. Geol., 294: 282-293. doi: 10.1016/j. sedgeo.2013.06.004.

Reis, A.H. and C. Gama. 2010. Sand size versus beachface slope - An explanation based on the Constructal Law. Geomorphology, 114: 276-283. doi: $\quad$ 10.1016/J.GEOMORPH.2009. 07.008 .

Rijn, V., L.C., P.K. Tonnon, and D.J.R. Walstra. 2011. Numerical modelling of erosion and accretion of plane sloping beaches at different scales. Coastal Engineering, 58(7): 637-655. doi:

10.1016/j.coastaleng.2011.01.009.

Rizal, S., P. Damm, M.A. Wahid, J. Sündermann, Y. Ilhamsyah, T. Iskandar, and Muhammad. 2012. General circulation in the Malacca Strait and Andaman Sea: A numerical model study. Am. J. Environ. Sci., 8: 479-488.

doi: 10.3844/ajessp.2012.479.488.

Samsuddin, M. 1989. Influence of Seasonal Changes on the Texture of Beach Sands, Southwest Coast of India. J. Coast. Res., 5: 57-64. Available at: http://www.jstor.org/stable/4297491.

Saniah, S., S. Purnawan, dan S. Karina. 2015.

Karakteristik dan kandungan mineral pasir pantai Lhok Mee, Beureunut dan Leungah, Kabupaten Aceh Besar. Depik, 3: 263-270. doi: 10.13170/depik.3.3.2176.

Schneider, S., J. Hornung, and M. Hinderer. 
2016. Evolution of the western East African Rift System reflected in provenance changes of Miocene to Pleistocene synrift sediments (Albertine Rift, Uganda). Sediment. Geol., 343: 190-205.

Schott, F.A., S.P. Xie, and J.P. McCreary Jr. 2009. Indian Ocean Circulation and Climate Variability. Rev. Geophys., 47: 1-46. doi: 10.1029/2007RG000245.

Shankar, D., P.N. Vinayachandran, and A.S. Unnikrishnan. 2002. The monsoon currents in the north Indian Ocean. Prog. Oceanogr., 52: 63-120. doi: 10.1016/S0079-6611(02)00024-1.

Sieh, K. and D. Natawidjaja. 2000. Neotectonics of the Sumatran fault, Indonesia. J. Geophys. Res. Solid Earth, 105: 28295-28326. doi: 10.1029/ 2000JB900120.

Sierra, C., G. Flor-Blanco, C. Ordoñez, G. Flor, and J.R. Gallego. 2017. Analyzing coastal environments by means of functional data analysis. Sediment. Geol., 357:99-108. doi: 10.1016/j. sedgeo.2017.06.008.

Šmejda, L., M. Hejcman, J. Horák, and I. Shai. 2017. Multi-element mapping of anthropogenically modified soils and sediments at the Bronze to Iron Ages site of Tel Burna in the southern Levant. Quat. Int., 1-13. doi: 10.1016/j.quaint. 2017.11.005.

Ueshima, M., D. Muslim, and M. Shibayama. 2013. Gamma ray dose rates in the Weh Island, Indonesia. Mem. Osaka Kyoiku Univ. Ser. III, Nat. Sci. Appl. Sci., 61: 17-22. Available at: https://inis.iaea.
org/search/search.aspx?orig_q=RN:461

35239 (Accessed: 5 April 2018).

Wachecka-Kotkowska, L. and P. Kotkowski. 2011. Grain-size distribution analysis of Quaternary sediments from the southern part of the Lodz region in Poland: a computational-methods approach. Geologos, 17:205-219. doi: 10.2478/v 10118-011-0012-7.

Wu, L., L. Mei, Y. Liu, J. Luo, C. Min, S. Lu, M. Li, and L. Guo. 2017. Multiple provenance of rift sediments in the composite basin-mountain system: Constraints from detrital zircon U-Pb geochronology and heavy minerals of the early Eocene Jianghan Basin, central China. Sediment. Geol., 349: 46-61. doi: 10.1016/j.sedgeo.2016.12.003.

Zahid, K.M. and D.L. Barbeau. 2010. Provenance of eastern Magallanes foreland basin sediments: Heavy mineral analysis reveals Paleogene tectonic unroofing of the Fuegian Andes hinterland. Sediment. Geol., 229:64-74. doi: 10.1016/j.sedgeo.2010.06.006.

Zulkarnain, J., A. Muhammad, Y. Halim, U. Urrilijanto, dan A. Manaf. 2000. Studi awal pengembangan pasir besi pesisir pantai Aceh sebagai bahan baku pembuatan material magnetik. in: Prosiding Simposium Fisika Nasional. Puspiptek - Serpong. 59-61 pp.

$\begin{array}{ll}\text { Diterima } & : 03 \text { Mei } 2018 \\ \text { Direview } & : 05 \text { Mei } 2018 \\ \text { Disetujui } & : \text { :05 Juli } 2018\end{array}$


